\title{
Oceanography
}

CITATION

Kappel, E.S. 2015. Quarterdeck: Launch of the new Oceanography website.

Oceanography 28(3):5, http://dx.doi.org/10.5670/oceanog.2015.68.

DOI

http://dx.doi.org/10.5670/oceanog.2015.68

COPYRIGHT

This article has been published in Oceanography, Volume 28, Number 3, a quarterly journal of The Oceanography Society. Copyright 2015 by The Oceanography Society. All rights reserved.

USAGE

Permission is granted to copy this article for use in teaching and research. Republication, systematic reproduction, or collective redistribution of any portion of this article by photocopy machine, reposting, or other means is permitted only with the approval of The Oceanography Society. Send all correspondence to: info@tos.org or The Oceanography Society, PO Box 1931, Rockville, MD 20849-1931, USA. 


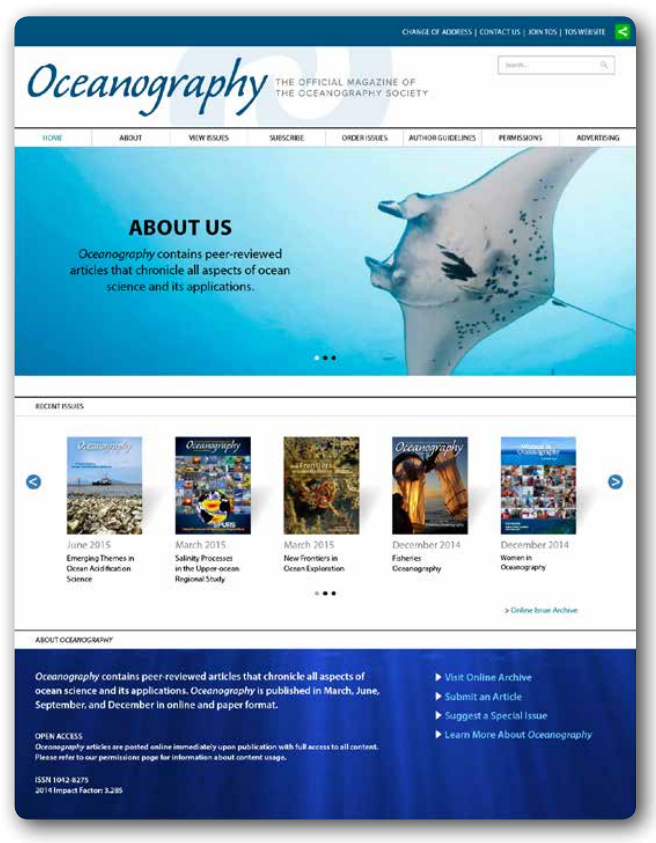

\section{Launch of the New Oceanography Website}

Over the last few months, The Oceanography Society has embarked on a project to update the Oceanography website (http://www.tos.org/oceanography). In addition to refreshing the site's look and feel, we want to provide the community with two important features: responsive design and citation export tools. Responsive design provides fully viewable and easily navigable Web pages whether you are on a big screen, laptop, tablet, or smart phone. The Web page resizes as the frame gets smaller or larger, depending on your device screen size or browser area, so that you don't have to scroll around to find information. Menus collapse to "hamburger" menus (those three horizontal lines in the upper right area of the screen) so that you have all options available, even on a small screen, without scrolling. Most journal websites have not transitioned to responsive design yet, but we feel strongly that it is an important step to take since users now search for information on a variety of devices. We also want the Oceanography pages to match the responsive design of the main TOS website. The planned citation export tools will provide users with the ability to download Oceanography citations to various applications such as EndNote, BibText, and Reference Manager. Our users have asked for this feature for a few years, and we are now pleased to be able to provide this tool for the community.

The new Oceanography website is scheduled to launch before the end of this year. We hope that you will exercise the site vigorously and notify me by email (at ekappel@geo-prose.com) about any bugs or broken links so that we can take care of those problems immediately. We also ask for your patience as links to article pages will be changing. If you link to specific Oceanography pages or urls already from your own Web pages, or have bookmarked pages, you may need to update those links. DOIs for articles will, of course, remain the same, but the specific urls they link to will be updated. We are doing everything we can to make sure that the website launch goes smoothly, and we apologize in advance for any inconvenience the updates may cause. Our goal is to provide the community with an attractive website that is easily navigable on all devices.

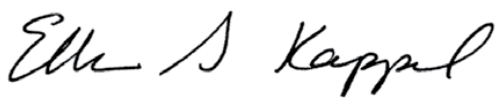

Ellen S. Kappel, Editor 